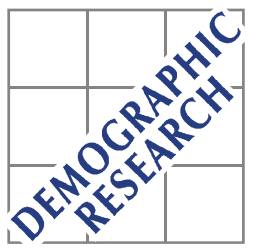

Demographic Research a free, expedited, online journal of peer-reviewed research and commentary in the population sciences published by the Max Planck Institute for Demographic Research Konrad-Zuse Str. 1, D-18057 Rostock · GERMANY www.demographic-research.org

DEMOGRAPHIC RESEARCH

VOLUME 22, ARTICLE 31, PAGES 985-1014

PUBLISHED O1 JUNE 2010

http://www.demographic-research.org/Volumes/Vol22/31/

DOI: $10.4054 /$ DemRes.2010.22.31

Research Article

\title{
Moving close to parents and adult children in the Netherlands: The influence of support needs
}

\section{Annika Smits}

(C) 2010 Annika Smits.

This open-access work is published under the terms of the Creative Commons Attribution NonCommercial License 2.0 Germany, which permits use, reproduction \& distribution in any medium for non-commercial purposes, provided the original author(s) and source are given credit.

See http:// creativecommons.org/licenses/by-nc/2.0/de/ 


\section{Table of Contents}

1 Introduction 986

$2 \quad$ Theoretical framework 987

$2.1 \quad$ Intergenerational solidarity and moving 987

2.2 Support needs associated with moving close to parents or children $\quad 988$

2.3 Other factors associated with moving 990

2.4 The Netherlands context 991

$3 \quad$ Data and method $\quad 991$

$\begin{array}{lll}3.1 & \text { Data } & 991\end{array}$

$\begin{array}{lll}3.2 & \text { Dependent variable } & 994\end{array}$

3.3 Independent variables 995

$\begin{array}{lll}3.4 & \text { Method } & 997\end{array}$

$4 \quad$ Results 1004

$\begin{array}{lll}5 & \text { Discussion } & 1007\end{array}$

6 Acknowledgements 1008

$\begin{array}{ll}\text { References } & 1009\end{array}$ 


\title{
Moving close to parents and adult children in the Netherlands: The influence of support needs
}

\author{
Annika Smits ${ }^{1}$
}

\begin{abstract}
In this paper, the extent to which support needs lead to moves of adult children (aged 30 and above) to within one kilometer of their parents and vice versa is examined. Using Netherlands population data from 2004 and 2005, it is found that the divorce of the adult child increases the likelihood of moving close to parents, especially in the event of recent divorce. A recent first birth in the adult child's household also leads to moving close to parents, whereas having children aged one and above makes moves of the parents close to the adult child more likely.
\end{abstract}

\footnotetext{
${ }^{1}$ University of Amsterdam. E-mail: a.w.m.smits@uva.nl
} 


\section{Introduction}

Despite the increasing individualization in western societies, the ties between parents and their adult children in terms of support and contact are still strong. The extent to which parents and children exchange support and maintain contact varies, particularly when they live close to each other (see for example Bordone 2009; Grundy and Shelton 2001; Hank 2007; Knijn and Liefbroer 2006; Mulder and Van der Meer 2009). Although living close to kin does not necessarily imply the exchange of support, certain types of support require the close proximity of a caregiver (Joseph and Chalmers 1996; Litwak 1985; Shelton and Grundy 2000). It is plausible, therefore, that parents and children move close to each other when either of them has an increased need for support or contact.

Yet, although a large amount of research addresses the importance of geographical proximity for kin support, only a few studies have considered the location of parents and children as triggers for moving. Furthermore, these studies mainly focus on the moves of only one of the two generations (of parents: Litwak and Longino 1987; Silverstein 1995; Rogerson, Burr, and Lin 1997; Van Diepen and Mulder 2009: of children: Michielin, Mulder, and Zorlu 2008). These studies leave open the question of which generation is more likely to move close to the other and whose support needs are better predictors for such a move. Other studies of the geographical proximity between parents and children have only investigated the decrease in the distance between them, failing to distinguish between those who move close (but still as far as a 15-minute drive away) and those who move very close (e.g., a 5-minute walk away) (Michielin, Mulder, and Zorlu 2008; Silverstein 1995; Rogerson, Burr, and Lin 1997). This deficiency is unfortunate because people who move very close to their parents or children are likely do so because they want to have close contact or exchange support, while people who move less close are more likely to have other motives for their move (Pettersson and Malmberg 2009). Moreover, even though it is likely that moving in with parents or children is associated with housing problems rather than with support needs, in previous research this type of move has not always been separated from other moves to be closer (Pettersson and Malmberg 2009; Rogerson, Burr, and Lin 1997; Silverstein 1995).

This paper addresses the following research question: To what extent do situations and events associated with parents' and their children's needs for support influence the likelihood of moving close to each other, and who, under what circumstances, is most likely to move close? I investigated whether parents and their adult children (ages 30 and above) in the Netherlands did not move, moved very close to the other generation (within a one-kilometer distance), close to the other generation (within more than one, and ten kilometers or less), or moved elsewhere between 2004 and 2005. Moves that 
resulted in coresidence have been excluded and analysed in a separate paper (Smits, van Gaalen, and Mulder forthcoming). The analyses have been performed using multinomial logistic regression models and data derived from the Social Statistical dataBase (SSB), which consists of rich administrative individual data for the entire Netherlands population.

\section{Theoretical framework}

\subsection{Intergenerational solidarity and moving}

Following the processes of individualization and urbanization, concern has been expressed that distances between family members will grow and family ties weaken (Burgess 1960; Cowgill 1974; Aboderin 2004). Nevertheless, recent studies have revealed that many older Europeans still live close to their adult children and maintain contact at least once a week (Hank 2007), and that intergenerational distances have not increased during the past decade (Malmberg and Pettersson 2007), at least not in Sweden.

Distances between parents and children are shaped by the moves of either generation during the life course (Lin and Rogerson 1995). For the younger generation, who move more frequently than the older, moves are often driven by life-course events such as entering the labour market or having a child (Mulder and Wagner 1998; Feijten and Mulder 2002). The proximity of kin is not necessarily required for these eventdriven moves, but may well be taken into account, especially by those with an increased need for support (Michielin, Mulder, and Zorlu 2008). For the older generation, mobility tends to decline towards retirement and grow slightly afterwards, where, following Litwak and Longino's (1987) developmental model, three categories can be distinguished: (a) moves to more attractive locations after retirement; (b) moves closer to kin following health problems or widowhood; and (c) moves to institutions.

For either generation, moving close to the other is likely to be influenced by the same determinants as those of any residential relocation. Moving is costly and resources are needed to initiate a move (Mulder 1993) in the first place. For this reason, the highly educated and the economically better-off are likely to have better opportunities to move than those who are less well off. Moreover, the degree to which people have accumulated location-specific capital in the area of their residential location decreases their likelihood of moving away (Da Vanzo 1981). Parents may be less likely to move away from their residential environment than are their children, because they will have had a longer duration of residence and accumulated more location-specific capital. It is also possible, however, that adult children have fewer possibilities to move away 
because they have strong ties to their residential environment for reasons of work or childcare. Regardless of who has the better opportunities to move, the support needs of either generation may lead to moves close to parents or children. I expected to find that the generation with the greater support needs would be the most likely to move. Thus, the support needs of the adult child were expected to be associated with the child's move close to the parents and the support needs of the parents with the parent's move close to the adult child.

\subsection{Support needs associated with moving close to parents or children}

Not only does the geographical proximity between parents and children facilitate the exchange of intergenerational support, but the distance between parents and children also decreases with increasing parental support needs (Silverstein 1995; Rogerson, Burr, and Lin 1997). In the United States, elderly parents with health problems tended to move closer to their offspring in order to receive their support (Longino et al. 1991; Serow and Sly 1991). In the Netherlands, adult children were found to move closer to parents in the case of a divorce or recent childbirth (Michielin, Mulder, and Zorlu 2008). It should be stressed that many support needs are likely to lead to moving in general, such as a move to a ground-floor apartment when climbing stairs becomes difficult or moving out of a formerly shared residence in the case of divorce. The aim of this paper is, however, to establish whether people with greater support needs are extra likely to move close to parents or children.

The need for support from parents or adult children might be less strong when a partner is present in the household, the person likely to be the first to turn to (Mulder and Van der Meer 2009). Furthermore, having a partner might reduce the likelihood of moving, because then the new residential location has to be advantageous for two people, both at risk of losing location-specific capital. It was, therefore, expected that unmarried (or unpartnered) children would be more likely to move close to their parents than partnered children would be. For the same reason, parents without a partner were also expected to be more likely to move close to their children than parents with a partner would be.

The loss of a partner through divorce or widowhood is likely to increase support needs. Divorced and widowed people were therefore expected to be more likely to move close to parents or adult children than were people who had a partner or those who had never married. The recent event of divorce was expected to be particularly likely to increase the need for support because of the health, economic, and social consequences (Amato 2000; Gram-Hanssen and Bech-Danielsen 2008). 
The presence of children in the household often involves stronger ties to a specific location, such as to the children's school and friends in the neighbourhood (Long 1972), which make moving away from that location less likely. However, these ties do not yet exist in the year following the first childbirth, when young parents are still likely to make adjustment moves (Deurloo, Clark, and Dieleman 1994; Mulder and Wagner 1998). When these adjustment moves are made, moving close to parents is likely to be an attractive possibility for those who need help with childcare and childrearing. I therefore expected that, compared with childless adult children, those with a recent first-born were more likely to move close to parents. Other adult children with children could be expected to be less likely than their childless counterparts to move close to parents, particularly those with children of school age. At the same time, the presence of children in the adult child's household might stimulate the parents to move close. That would facilitate fulfilling their desire to spend time with their grandchildren and to provide support when needed (Lin and Rogerson 1995). The help of parents in the provision of childcare for grandchildren might be particularly needed when the grandchildren are below school age (four or younger).

Health problems or problems with performing activities of daily living are likely to generate support needs that require the proximity of a caregiver (Litwak 1985; Joseph and Chalmers 1996) and might be associated with a move close to parents or children. Unfortunately, the data used did not contain information about problems with activities of daily living, but did reveal whether people received a disability benefit. Dependence on a disability benefit was expected to be associated with a move close to parents or children.

It can be hypothesised that children and parents who have a high income (and are able to buy care on the market when needed) have a less strong need for the proximity of kin. Also, people with higher incomes are likely to have specialized jobs, which are more widely dispersed than non-specialized jobs. People with higher incomes might find moving away from their place of residence difficult and would be less likely to move close to parents or adult children. It was also expected that adult children and parents who depend on social security benefits or who do not receive any income from labor or social security benefits would be more likely to move close to kin because they are more likely than their employed counterparts to have increased support needs (see also Hank 2007).

Because women tend to be the kin-keepers in the family (Rossi and Rossi 1990) and are more often the caregivers of their (elderly) parents than men are (Joseph and Hallman 1998; Rogerson, Burr, and Lin 1997), I expected parents to be more likely to move close to a daughter than to a son. In line with this argument, daughters could be expected to be more likely than sons to move close to parents, although daughters might also be less likely to move close to parents because females tend to move to the place of 
residence of their male employed partner (Mulder and Wagner 1993; Boyle, Halfacree, and Robinson 1998).

Moving close to parents was expected to be more likely when other siblings already live close to parents, because the presence of siblings may add extra value to the parents' location (Michielin, Mulder, and Zorlu 2008). For the parents, however, the likelihood of moving close to an adult child is probably smaller when at least one other child already lives close because contact and care might have already been provided for by this alternative caregiver (Mulder and Van der Meer 2009). The absence of such alternative caregivers was expected to increase the likelihood that only children move close to parents and that parents move close to their only child.

\subsection{Other factors associated with moving}

An important factor associated with moves close to parents and children is level of education. Highly educated children are likely to have higher incomes and thus have better resources to move (Mulder 1993). Mobility is also known to decrease with increasing age. Furthermore, the parents' likelihood to move close to children was expected to decrease with age because older adults were usually found to be satisfied with their home and residential environment and so less likely to move away (Rogerson, Burr, and Lin 1997).

The direction of the effect of having moved recently was not clear beforehand. On the one hand, I expected the likelihood of moving close to parents or children to be lower for people who had moved only recently, since moving is costly. On the other hand, the longer people have lived somewhere, the less likely it is that they move away from that location (Clark and Dieleman 1996). Furthermore, I expected homeowners to be less likely to move close to kin than renters, because homeowners are more strongly tied to their residential environment than are renters (Speare, Goldstein, and Frey 1975; Courgeau 1985; Helderman, Van Ham, and Mulder 2006).

I expected adult children and parents who live in rural areas to be more likely to move close to kin, since people raised in rural areas were found to express stronger filial responsibility than were those raised in urban areas (Lee, Coward, and Netzer 1994). Immigrants have been found to live at a short distance from family members in their host country, provided they have family members living in the same country (Michielin and Mulder 2007). Also, migrants from non-Western countries in the Netherlands were found to have stronger family norms than the native Dutch (Liefbroer and Mulder 2006), which could make them more likely to move close to other family members. 


\subsection{The Netherlands context}

Some understanding of the Netherlands context is relevant to frame the above expectations about moves close to kin. In the Netherlands, the average distance between parents and children is about 29 kilometers, with $32 \%$ of the population having at least one family member (including siblings and parents-in-law) living no further than one kilometer away (Mulder and Kalmijn 2006). The extent to which support is exchanged differs markedly, depending on how far away parents and children live from each other. In the Netherlands, parents who lived five or more kilometers away from their children were considerably less likely to receive help with household chores and odd jobs than parents who lived within five kilometers of an adult child (Knijn and Liefbroer 2006).

The Netherlands' built environment can be characterized as relatively urbanised, meaning that there are almost no remote rural areas. Owner-occupied housing prevails in the more rural areas, whereas housing in the larger cities is often dominated by the social rental sector.

\section{Data and method}

\subsection{Data}

The empirical analyses are based on the Social Statistical dataBase (SSB) provided by Statistics Netherlands (see Bakker 2002 for a description of the SSB). The database includes population register data and other administrative data on the entire Netherlands population, including address registration data. Record linkage between individual records and those of the parents allows for the reconstruction of parent-child networks, although not all parents could be traced in the registers. Record linkage was successful when the parent and child had ever lived in the same municipality after October $1^{\text {st }}$, 1994 or, failing that, the dates of birth of both parents were known, which was the case had the parents ever married and were both alive in October 1994. Hence, older birth cohorts are underrepresented in the data, while parents and children who live in the same municipality are overrepresented. To avoid problems with data selectivity, I only selected adult children who had both parents alive in 1995. The models were also run separately for children and parents who lived in the same municipality and were thus fully represented in the data. The results of these analyses were not substantially different. Unfortunately, the data do not include direct information on support needs. Instead, I used situations and events that are associated with support needs. Despite the lack of information on actual support needs, because of its large size the SSB is 
considered a very suitable database for the investigation of a rather uncommon event like moving close to parents or children.

The focus of the analyses was on the moves of children and parents that took place between September 2004 and September 2005. Children aged 30 and above, not living in the parental home and with at least one parent alive during this whole period were selected. Children aged 30 and below were excluded from the dataset because many of them still lived in the parental home. Furthermore, parents older than 90 and those who had their first child at age 18 or younger were excluded because they were considered to be select groups.

Children who already lived within one kilometer of their parents in 2004 were excluded from the analyses. This was the case for $821,700^{2}$ children $(22.5 \%$ of all people in the data). Table 1 provides an overview of selected descriptive measures for parents and children who lived within one kilometer of each other in 2004 and those who did not. Compared with parents and children who lived farther away, those living at a distance of maximum one kilometer were more often the recipients of a disability benefit or other benefits, were less often employed, and had lower incomes. Parents and children who lived within a one kilometer distance in 2004 were also slightly younger, less often homeowners, more often rural residents, and more often non-Western migrants than those living further away. These results are in line with previous research in which people with a low socioeconomic position were found to be more likely to live close to parents or adult children (for the United States: Clark and Wolf 1992. For several European countries: Hank 2007. For Sweden: Malmberg and Pettersson 2007). The vast majority (94\%) of the parents and children who already lived at a one kilometer distance in 2004 remained in the same area in 2005. About $4.5 \%$ remained within a ten kilometer distance and almost $1.5 \%$ moved to a distance of more than ten kilometers.

The analyses were performed after a listwise exclusion of 38,400 missing values on parental income, 17,500 on parental housing tenure, and 15,900 on the adult child's housing tenure, which resulted in $2,725,400$ observations.

\footnotetext{
${ }^{2}$ Note that, for reasons of data protection, all counts presented in this paper are rounded off to hundreds.
} 
Table 1: Comparison of children and parents who were included in the analyses $(N=2,725,400)$ and those who were excluded because they already lived within a one kilometer distance in $2004(\mathrm{n}=$ 821,700)

\begin{tabular}{|c|c|c|}
\hline & \multicolumn{2}{|c|}{$\%(M, S D)$} \\
\hline & Included in analyses & $\leq 1 \mathrm{~km}$ in 2004 \\
\hline \multicolumn{3}{|c|}{$\begin{array}{l}\text { Situations and events associated with support } \\
\text { needs }\end{array}$} \\
\hline \multicolumn{3}{|l|}{ Child's labor-market position } \\
\hline Receives disability benefit & 4.12 & 4.93 \\
\hline Self-employed & 7.55 & 8.69 \\
\hline Employed & 73.76 & 69.98 \\
\hline Receives other benefit & 5.47 & 6.59 \\
\hline Economically inactive & 9.10 & 9.81 \\
\hline Child's income & $1.07 ; 0.55$ & $0.98 ; 0.51$ \\
\hline \multicolumn{3}{|l|}{ Parental labor-market position } \\
\hline Parent receives disability benefit & 7.42 & 9.30 \\
\hline Parent is self-employed & 3.02 & 3.66 \\
\hline Parent is retired & 76.15 & 71.49 \\
\hline Parent is employed & 10.47 & 10.98 \\
\hline Parent receives other benefit & 2.94 & 4.57 \\
\hline Parental income & $0.94 ; 0.37$ & $0.88 ; 0.34$ \\
\hline Child is only child & 11.57 & 13.50 \\
\hline \multicolumn{3}{|l|}{ Control variables } \\
\hline Age of child & $40.81 ; 7.49$ & $39.89 ; 7.32$ \\
\hline Age of oldest parent & $70.13 ; 8.66$ & $69.09 ; 8.70$ \\
\hline Child is homeowner & 70.45 & 64.02 \\
\hline Parent is homeowner & 50.40 & 48.10 \\
\hline Child is rural resident & 55.06 & 66.67 \\
\hline Parent is rural resident & 59.18 & 66.65 \\
\hline \multicolumn{3}{|l|}{ Child's migrant status } \\
\hline Non-migrant & 90.79 & 89.57 \\
\hline Non-Western migrant & 2.95 & 5.17 \\
\hline Western migrant & 6.26 & 5.25 \\
\hline
\end{tabular}

Note: Income (logged) was derived from individual monthly tax incomes. Ages are measured in years. 


\subsection{Dependent variable}

The moves of parents and children were measured according to four categories: $0=n o$ move, $1=$ moves very close, $2=$ moves close, and $3=$ moves elsewhere. The choice of this measure is based on the assumption that "the decision about moving and the choice of the destination location will be part of one decision" (Michielin, Mulder and Zorlu 2008:334). Not moving was therefore included as a separate category in the dependent variable, in addition to moves very close, moves close, and moves elsewhere. Moves very close were defined as moves from five kilometers or further away to within a onekilometer distance. Note that moves that resulted in coresidence were not included in the analyses. The choice of a distance threshold of one kilometer makes it plausible that moves very close to parents or adult children were related to support needs or the wish to maintain contact rather than to other motives. Furthermore, living within one kilometer facilitates the realization of face-to-face contact within a ten-minute walk (or a three-minute bike ride); so that assistance at home can be provided relatively quickly. Support needs that require such close proximity of a caregiver include helping someone up and down stairs, getting dressed, cooking, and shopping. A category 'moves close' (moves to within between more than one and ten kilometers or less) was constructed to separate the distances for which the provision of care is still feasible on a daily basis from those for which the provision of daily care is not plausible. For parents and children who already lived within five kilometers in 2004, it was not plausible that moves to within one kilometer were more strongly related to support needs than to other motives (such as moves to larger homes within the same area). For this reason, these moves have been categorized as moves close. Moves elsewhere were defined as moves to a distance of over ten kilometers. The distribution of the dependent variable becomes clear from Table 2.

Table 2: Children's and parents' moves between 2004 and 2005, percentages, $\mathrm{N}=\mathbf{2 , 7 2 5 , 4 0 0}$

\begin{tabular}{lrrrr}
\hline & \multicolumn{2}{c}{ Children's moves } & \multicolumn{2}{c}{ Parents' moves } \\
\cline { 2 - 5 } & \% of total & \% of movers & \% of total & \% of movers \\
\hline No move & 92.32 & & 95.46 & \\
To within 1 kilometer & 0.19 & 2.51 & 0.13 & 2.84 \\
To 1 - $\leq$ 10 kilometers & 3.16 & 41.17 & 2.13 & 46.77 \\
To > 10 kilometers & 4.33 & 56.32 & 2.29 & 50.39 \\
\hline
\end{tabular}


Distances (along a straight line) between the child and the parents were calculated using the geographical coordinates of the centre of each six-digit postal code area. For the parents, the location used was that of both registered parents when they were living together, or that of the only parent living in the Netherlands, or of a randomly-chosen parent when the parents lived apart in 2005. Note that when parents lived apart in 2005, other parental covariates included in the models referred to the randomly-chosen parent as well. To check whether the results would be different for mothers and fathers, I performed additional analyses for mothers and fathers separately (results not shown). These models differed only marginally from the models presented in this paper.

\subsection{Independent variables}

The explanatory variables used in the analyses included the household situation, the presence of children in the adult child's household, labor-market position, income (as a logarithm), the gender of the adult child, whether parents had (at least) one other child living close (within one kilometer, including coresidence), and whether the adult child was an only child. Unfortunately, level of education was not available in the data. The categorization of the variables is shown in Table 3 .

Table 3: Descriptive measures of variables used in the analyses of children's and parents' moves, $N=\mathbf{2 , 7 2 5 , 4 0 0}$

\begin{tabular}{lr}
\hline & $\%(\boldsymbol{M}, \mathbf{S D})$ \\
\hline Situations and events associated with support needs & \\
Child's household situation & 80.08 \\
With partner & 13.19 \\
Never married single & 0.64 \\
Widowed single & 5.43 \\
Divorced single & 0.67 \\
Divorced '04-'05 & \\
Child has children in the household & 36.30 \\
No children & 4.83 \\
Recently first child & 15.32 \\
Children aged 1 to 4 & 43.56 \\
Children above age 4 & \\
Child's labor-market position & 4.12 \\
Receives disability benefit & 7.55 \\
Self-employed & 73.76 \\
Employed & \\
\hline
\end{tabular}


Smits: Moving close to parents and adult children in the Netherlands: The influence of support needs

Table 3: (Continued)

\begin{tabular}{|c|c|}
\hline & $\%(M, S D)$ \\
\hline Receives other benefit & 5.47 \\
\hline Economically inactive & 9.10 \\
\hline Child's income & $1.07 ; 0.55$ \\
\hline \multicolumn{2}{|l|}{ Parental household situation } \\
\hline Parents together & 63.34 \\
\hline Mother has new partner & 3.29 \\
\hline Mother widowed & 16.71 \\
\hline Mother divorced or never-married & 4.81 \\
\hline Mother divorced '04-'05 & 0.02 \\
\hline Father has new partner & 4.09 \\
\hline Father widower & 4.84 \\
\hline Father divorced or never-married & 2.88 \\
\hline Father divorced '04-'05 & 0.03 \\
\hline \multicolumn{2}{|l|}{ Parental labor-market position } \\
\hline Parent receives disability benefit & 7.42 \\
\hline Parent is self-employed & 3.02 \\
\hline Parent is retired & 76.15 \\
\hline Parent is employed & 10.47 \\
\hline Parent receives other benefit & 2.94 \\
\hline Parental income & $0.94 ; 0.37$ \\
\hline Child is female & 50.47 \\
\hline Parents have other child living close & 27.74 \\
\hline Child is only child & 11.57 \\
\hline \multicolumn{2}{|l|}{ Control variables } \\
\hline Age of child & $40.81 ; 7.49$ \\
\hline Age of oldest parent & $70.13 ; 8.66$ \\
\hline Age difference & 29.32; 5.07 \\
\hline Child has recently moved & 22.07 \\
\hline Parent has recently moved & 10.02 \\
\hline Child is homeowner & 70.45 \\
\hline Parent is homeowner & 50.40 \\
\hline Child is rural resident & 55.06 \\
\hline Parent is rural resident & 59.18 \\
\hline \multicolumn{2}{|l|}{ Child's migrant status } \\
\hline Non-migrant & 90.79 \\
\hline Non-Western migrant & 2.95 \\
\hline Western migrant & 6.26 \\
\hline
\end{tabular}

Note: Income (logged) was derived from individual monthly tax incomes. Ages are measured in years. 
'Household situation' included the event of divorce, measured as a change in marital status from married to divorced between in 2004 and 2005. The labor-market position of the child and that of the parents included a measurement of receiving a disability benefit. People receive this in the Netherlands if they are unable to earn a full income owing to sickness or a handicap. There was also a measurement of being economically inactive, which corresponds to receiving no income from labor or socialsecurity benefits. 'Being retired' was measured in a separate category for the parents, but not for the adult child because very few adult children in the data were retirees. Parents or children who received benefits other than disability benefits and retirement benefits (for example unemployment benefits or other social security benefits), were grouped together in one category: 'receives other benefit.' When both parents lived together, the labor-market position that was considered to be most strongly associated with the parents' support needs was used. The categories ranged from receiving a disability benefit to receiving other benefits or being inactive. Income was taken from the individual tax income in euro per month. Negative incomes and incomes of zero were set at zero in the logarithmic measure. When both parents were alive and living together, the mean of their incomes was used.

When no specification is given, the control variables in the models refer to whoever the analysis pertains to: the adult child in the model of the child's moves and the parents in the model of the parents' moves. Included as control variables were: age (as a linear and a quadratic term), age difference from the oldest parent, having moved recently (between 2001 and 2004), being a homeowner, living in a rural area (defined as an area with fewer than 1000 addresses per square kilometer), and the child's migrant status (where first- and second-generation migrants are grouped together and labelled as either non-Western migrants or Western migrants).

\subsection{Method}

To get an impression of the mobility among parents and children, I first carried out some bivariate analyses. Table 4 provides an overview of the moves of adult children and Table 5 describes those of their parents by selected situations associated with support needs. The tables show how much mobility there is among several support need categories, and how much of the mobility goes in the direction of parents and children. 
Table 4: Children's moves between 2004 and 2005 by selected support need categories, percentages, $N=2,725,400$

\begin{tabular}{|c|c|c|c|c|c|}
\hline & $\begin{array}{c}n \text { per } \\
\text { category }\end{array}$ & No move & $\leq 1 \mathrm{~km}$ & $\begin{array}{c}1-\leq 10 \\
\mathrm{~km}\end{array}$ & $>10 \mathrm{~km}$ \\
\hline \multicolumn{6}{|l|}{ Child's household situation } \\
\hline With partner & $2,182,500$ & 93.83 & 0.16 & 2.63 & 3.39 \\
\hline Never married single & 359,300 & 86.83 & 0.29 & 4.81 & 8.06 \\
\hline Widowed single & 17,500 & 93.71 & 0.15 & 2.62 & 3.52 \\
\hline Divorced single & 147,900 & 86.98 & 0.32 & 5.26 & 7.45 \\
\hline Divorced '04-'05 & 18,200 & 60.79 & 1.53 & 18.60 & 19.08 \\
\hline \multicolumn{6}{|l|}{ Child has children in household } \\
\hline No children & 989,200 & 89.88 & 0.24 & 3.78 & 6.10 \\
\hline Recently first child & 131,500 & 88.44 & 0.35 & 4.43 & 6.78 \\
\hline Children aged 1 to 4 & 417,500 & 91.79 & 0.27 & 3.61 & 4.32 \\
\hline Children above age 4 & $1,187,200$ & 94.96 & 0.11 & 2.35 & 2.58 \\
\hline \multicolumn{6}{|l|}{ Child's labor-market position } \\
\hline Receives disability benefit & 112,300 & 91.85 & 0.24 & 3.47 & 4.43 \\
\hline Self-employed & 205,800 & 92.66 & 0.17 & 3.10 & 4.07 \\
\hline Employed & $2,010,100$ & 92.23 & 0.19 & 3.18 & 4.40 \\
\hline Receives other benefit & 149,100 & 91.02 & 0.25 & 3.77 & 4.96 \\
\hline Economically inactive & 148,100 & 93.72 & 0.18 & 2.54 & 3.56 \\
\hline Child is female & $1,375,600$ & 92.66 & 0.20 & 2.99 & 4.16 \\
\hline Parents have other child living close & 756,000 & 93.41 & 0.24 & 3.18 & 3.16 \\
\hline Child is only child & 315,400 & 89.57 & 0.29 & 4.23 & 5.91 \\
\hline Total & $2,725,400$ & 92.33 & 0.19 & 3.16 & 4.33 \\
\hline
\end{tabular}

From Table 4 it becomes clear that the share of adult children moving close to their parents is particularly large among children who have divorced between 2004 and 2005, who recently had their first child, who receive benefits, who have a sibling living close to their parents, and who are only children. It should be noted that a large majority of adult children did not move at all. Among the movers, moves to a distance of over ten kilometers are most prevalent for all support need categories. Also most of the parents did not move between 2004 and 2005 (Table 5). Among the movers, moves to a distance of over ten kilometers are most prevalent for almost all support need categories. Only among the parents who are together, who receive a disability benefit, who are self-employed, and who have another child living close, moves to one to tenkilometer distances are more prevalent. Table 5 also shows that the share of parents moving close to an adult child is particularly large among mothers with a new partner, parents who receive benefits, and parents with an only child. 
Table 5: Parents' moves between 2004 and 2005 by selected support need categories, percentages, $N=2,725,400$

\begin{tabular}{|c|c|c|c|c|c|}
\hline & $\begin{array}{c}n \text { per } \\
\text { category }\end{array}$ & No move & $\leq 1 \mathrm{~km}$ & $\begin{array}{c}1-\leq 10 \\
\mathrm{~km}\end{array}$ & $>10$ km \\
\hline \multicolumn{6}{|l|}{ Parental household situation } \\
\hline Parents together & $1,726,300$ & 96.70 & 0.11 & 1.61 & 1.58 \\
\hline Mother has new partner & 89,500 & 91.91 & 0.23 & 3.64 & 4.22 \\
\hline Mother widowed & 455,500 & 93.86 & 0.16 & 2.97 & 3.01 \\
\hline Mother divorced or never-married & 131,000 & 93.23 & 0.21 & 3.17 & 3.39 \\
\hline Mother divorced '04-'05 & 500 & 73.54 & 0.20 & 10.91 & 15.35 \\
\hline Father has new partner & 111,500 & 93.30 & 0.10 & 2.41 & 4.19 \\
\hline Father widower & 131,800 & 93.54 & 0.13 & 2.90 & 3.43 \\
\hline Father divorced or never-married & 78,600 & 91.69 & 0.16 & 3.31 & 4.84 \\
\hline Father divorced '04-'05 & 700 & 73.69 & 0.15 & 9.59 & 16.57 \\
\hline \multicolumn{6}{|l|}{ Parental labor-market position } \\
\hline Parent receives disability benefit & 202,200 & 95.42 & 0.17 & 2.25 & 2.16 \\
\hline Parent is self-employed & 82,300 & 96.06 & 0.11 & 1.92 & 1.91 \\
\hline Parent is retired & $2,075,300$ & 95.33 & 0.12 & 2.18 & 2.36 \\
\hline Parent is employed & 285,500 & 96.31 & 0.12 & 1.64 & 1.93 \\
\hline Parent receives other benefit & 80,100 & 95.14 & 0.18 & 2.29 & 2.40 \\
\hline Child is female & & 95.45 & 0.15 & 2.12 & 2.28 \\
\hline Parents have other child living close & 756,000 & 95.70 & 0.07 & 2.33 & 1.89 \\
\hline Child is only child & 315,400 & 95.85 & 0.18 & 1.94 & 2.03 \\
\hline Total & $2,725,400$ & 95.46 & 0.13 & 2.13 & 2.29 \\
\hline
\end{tabular}

In a second step, two multinomial logistic regressions were performed: one for the moves of the child and the other for those of the parents. Standard errors were corrected for the clustering of adult children with the same parents. The results from these regressions are presented in Table 6 (the child's moves) and Table 7 (the moves of the parents). The first three columns of these tables report the parameters for moves very close to the other generation $(\leq 1 \mathrm{~km})$, moves close to $(1-\leq 10 \mathrm{~km})$, and moves elsewhere $(>10 \mathrm{~km})$, with 'no move' as the reference category. To test whether the coefficients of 'moves very close' differed significantly from those of 'moves elsewhere,' additional analyses were performed with 'moves elsewhere' as the reference category (reported in the fourth column of Tables 6 and 7). 
Smits: Moving close to parents and adult children in the Netherlands: The influence of support needs

Table 6: Multinomial logistic regression for the moves of the adult child between 2004 and 2005 (ref=not moving), relative risk ratios

\begin{tabular}{|c|c|c|c|c|c|c|c|c|}
\hline \multirow{3}{*}{$\begin{array}{l}\text { Situations and events associated wit } \\
\text { support needs }\end{array}$} & \multicolumn{8}{|c|}{ Moves of the child } \\
\hline & \multicolumn{2}{|c|}{ Very close } & \multicolumn{2}{|l|}{ Close } & \multicolumn{2}{|c|}{ Elsewhere } & \multicolumn{2}{|c|}{ Very close ${ }^{k}$} \\
\hline & & & & & & & & \\
\hline \multicolumn{9}{|l|}{ Child's household situation $^{a}$} \\
\hline Never married single & 1.34 & ** & 1.23 & ** & 1.30 & ** & 1.03 & \\
\hline Widowed single & 1.87 & * & 1.73 & $* *$ & 1.39 & ** & 1.35 & \\
\hline Divorced single & 3.36 & ** & 2.73 & $* *$ & 2.68 & ** & 1.26 & ** \\
\hline Divorced '04-'05 & 18.57 & $* *$ & 12.30 & $* *$ & 9.26 & ** & 2.01 & ** \\
\hline \multicolumn{9}{|l|}{ Children in the child's household ${ }^{a}$} \\
\hline Recently first child & 1.23 & ** & 1.10 & ** & 1.14 & ** & 1.08 & \\
\hline Children aged 1 to 4 & 0.90 & & 0.83 & $* *$ & 0.70 & ** & 1.28 & $* *$ \\
\hline Children above age 4 & 0.53 & $* *$ & 0.72 & $* *$ & 0.53 & ** & 1.00 & \\
\hline \multicolumn{9}{|l|}{ Child's labor-market position ${ }^{a}$} \\
\hline Receives disability benefit & 1.20 & * & 0.96 & & 1.03 & & 1.17 & \\
\hline Self-employed & 0.98 & & 1.01 & & 1.08 & ** & 0.91 & \\
\hline Receives other benefit & 1.16 & & 0.92 & $* *$ & 1.04 & * & 1.11 & \\
\hline Economically inactive & 1.08 & & 0.84 & $* *$ & 1.69 & ** & 0.64 & ** \\
\hline Child's income & 0.98 & & 0.90 & $* *$ & 1.59 & ** & 0.62 & $* *$ \\
\hline \multicolumn{9}{|l|}{ Parental household situation $^{a}$} \\
\hline Mother has new partner & 0.95 & & 0.93 & ** & 1.29 & ** & 0.73 & ** \\
\hline Mother widowed & 0.96 & & 1.04 & $* *$ & 0.93 & * & 1.02 & \\
\hline Mother divorced or never-married & 0.94 & & 1.11 & $* *$ & 1.22 & ** & 0.77 & $* *$ \\
\hline Mother divorced '04-'05 & 0.64 & & 1.01 & & 1.15 & & 0.55 & \\
\hline Father has new partner & 0.55 & ** & 0.88 & ** & 1.33 & ** & 0.42 & ** \\
\hline Father widower & 0.96 & & 1.10 & ** & 0.95 & & 1.01 & \\
\hline Father divorced or never-married & 0.68 & ** & 0.98 & & 1.19 & ** & 0.57 & ** \\
\hline Father divorced '04-'05 & 1.52 & & 0.99 & & 1.60 & * & 0.97 & \\
\hline \multicolumn{9}{|l|}{ Parental labor-market position ${ }^{a}$} \\
\hline Receives disability benefit & 1.08 & & 1.00 & & 1.05 & * & 1.03 & \\
\hline Self-employed & 0.92 & & 0.91 & ** & 1.00 & & 0.93 & \\
\hline Retired & 0.98 & & 0.96 & * & 1.07 & ** & 0.92 & \\
\hline Receives other benefit & 1.10 & & 1.02 & & 1.01 & & 1.09 & \\
\hline
\end{tabular}


Table 6: (Continued)

\begin{tabular}{|c|c|c|c|c|c|c|c|c|}
\hline \multirow{3}{*}{ Parental income } & \multicolumn{8}{|c|}{ Moves of the child } \\
\hline & \multicolumn{2}{|c|}{ Very close } & \multicolumn{2}{|l|}{ Close } & \multicolumn{2}{|c|}{ Elsewhere } & \multicolumn{2}{|c|}{ Very close } \\
\hline & 1.05 & & 0.81 & & 1.37 & ** & 0.77 & ** \\
\hline Child is female & 1.00 & & 0.82 & ** & 1.06 & ** & 0.95 & \\
\hline Parents have other child living close & 1.76 & ** & 1.14 & ** & 0.83 & ** & 2.13 & ** \\
\hline Child is only child & 1.10 & & 0.99 & & 0.95 & ** & 1.16 & * \\
\hline \multicolumn{9}{|l|}{ Control variables } \\
\hline Age & 0.72 & $* *$ & 0.79 & ** & 0.84 & ** & 0.86 & ** \\
\hline Age squared & 1.01 & $* *$ & 1.01 & ** & 1.01 & ** & 1.01 & ** \\
\hline Age difference & 0.97 & $* *$ & 0.98 & ** & 1.00 & & 0.97 & ** \\
\hline Has recently moved & 0.01 & $* *$ & 0.01 & ** & 0.01 & $* *$ & 1.26 & \\
\hline Homeowner & 0.77 & ** & 0.65 & ** & 0.59 & ** & 1.31 & ** \\
\hline Rural resident & 1.07 & & 0.84 & ** & 0.75 & ** & 1.43 & $* *$ \\
\hline \multicolumn{9}{|l|}{ Child's migrant status $^{a}$} \\
\hline non-Western migrant & 1.04 & & 1.09 & ** & 0.83 & $* *$ & 1.25 & * \\
\hline Western migrant & 1.03 & & 1.05 & ** & 1.10 & ** & 0.94 & \\
\hline $\mathrm{N}$ & \multicolumn{8}{|c|}{$2,725,400$} \\
\hline df & \multicolumn{8}{|c|}{108} \\
\hline$x^{2}$ & \multicolumn{8}{|c|}{140,729} \\
\hline
\end{tabular}

Note: The standard errors are corrected for the clustering of children with the same mother.

${ }^{a}$ Reference categories: with partner; no child, employed; parents together; parents employed; native Dutch. ${ }^{\text {b Parameters for }}$ moving close, with moving elsewhere as the reference category.

${ }^{*} p<.01{ }^{* *} p<.001$

To examine whether certain independent variables had greater parameters for parents than for children or the other way around, I used seemingly unrelated estimations of the two models (Clogg, Petkova, and Haritou 1995; Weesie 1999). With this procedure, the coefficients and standard errors of the two models are estimated simultaneously. In the first column of Table 7, the indicator $\left({ }^{c}\right)$ specifies whether the coefficients of moving close in the model for parents differ significantly from those in the model for adult children. Note that, because the parents' and the children's models are being estimated simultaneously, the characteristics of some people appear in the data twice (once as an adult child and once as a parent). I do not expect this to be problematic, because this holds for not even $0.5 \%$ of the people. 
Even though the data were not derived from a sample, but from a complete population, significance levels are reported because the data can be regarded as a onemoment sample from a theoretical population of many time points.

Table 7: Multinomial logistic regression for the moves of the parents between 2004 and 2005 (ref=not moving), relative risk ratios

\begin{tabular}{|c|c|c|c|c|c|c|c|c|}
\hline \multirow{3}{*}{$\begin{array}{l} \\
\text { Situations and events associated wit } \\
\text { support needs }\end{array}$} & \multicolumn{8}{|c|}{ Moves of the parents } \\
\hline & \multicolumn{2}{|c|}{ Very close } & \multicolumn{2}{|l|}{ Close } & \multicolumn{2}{|c|}{ Elsewhere } & \multicolumn{2}{|c|}{ Very close $e^{b}$} \\
\hline & & & & & & & & \\
\hline \multicolumn{9}{|l|}{ Child's household situation $^{a}$} \\
\hline Never married single & $0.81^{c}$ & * & 0.90 & ** & 0.93 & ** & 0.87 & \\
\hline Widowed single & 1.31 & & 1.23 & & 0.82 & ** & 1.60 & \\
\hline Divorced single & $0.97^{\mathrm{C}}$ & & 1.04 & & 1.02 & & 0.95 & \\
\hline Divorced '04-'05 & $1.11^{\mathrm{c}}$ & & 0.99 & & 1.09 & & 1.01 & \\
\hline \multicolumn{9}{|l|}{ Children in the child's household ${ }^{a}$} \\
\hline Recently first child & 1.10 & & 0.94 & * & 0.92 & ** & 1.20 & \\
\hline Children aged 1 to 4 & $1.42^{\mathrm{C}}$ & ** & 1.03 & & 0.87 & ** & 1.63 & ** \\
\hline Children above age 4 & $1.26^{\mathrm{C}}$ & ** & 1.15 & ** & 0.90 & & 1.39 & ** \\
\hline \multicolumn{9}{|l|}{ Child's labor-market position ${ }^{a}$} \\
\hline Receives disability benefit & 1.14 & & 1.01 & & 1.09 & ** & 1.04 & \\
\hline Self-employed & 1.10 & & 0.95 & ** & 0.96 & & 1.14 & \\
\hline Receives other benefit & 1.03 & & 0.97 & & 1.09 & ** & 0.95 & \\
\hline Economically inactive & 0.91 & & 0.76 & ** & 1.23 & ** & 0.74 & ** \\
\hline Child's income & 0.84 & ** & 0.73 & ** & 0.95 & ** & 0.71 & ** \\
\hline \multicolumn{9}{|l|}{ Parental household situation ${ }^{a}$} \\
\hline Mother has new partner & $2.17^{\mathrm{C}}$ & ** & 2.11 & ** & 2.91 & $* *$ & 0.74 & * \\
\hline Mother widowed & $1.62^{\mathrm{C}}$ & ** & 1.81 & ** & 1.69 & $* *$ & 0.96 & \\
\hline Mother divorced or never-married & $1.90^{\mathrm{C}}$ & ** & 1.93 & ** & 2.39 & $* *$ & 0.79 & * \\
\hline Mother divorced '04-'05 & 3.16 & & 12.24 & ** & 22.09 & ** & 0.14 & \\
\hline Father has new partner & 0.78 & & 1.53 & ** & 2.50 & ** & 0.31 & ** \\
\hline Father widower & 1.10 & & 1.50 & ** & 1.50 & ** & 0.73 & * \\
\hline Father divorced or never-married & $1.37^{\mathrm{C}}$ & * & 2.02 & ** & 3.02 & ** & 0.45 & ** \\
\hline Father divorced '04-'05 & 1.60 & & 8.65 & $* *$ & 14.91 & ** & 0.11 & \\
\hline
\end{tabular}


Table 7: (Continued)

\begin{tabular}{|c|c|c|c|c|c|c|c|c|}
\hline \multirow{3}{*}{ Parental labor-market position $^{a}$} & \multicolumn{8}{|c|}{ Moves of the parents } \\
\hline & \multicolumn{2}{|c|}{ Very close } & \multicolumn{2}{|l|}{ Close } & \multicolumn{2}{|c|}{ Elsewhere } & \multicolumn{2}{|c|}{ Very close $^{b}$} \\
\hline & & & & & & & & \\
\hline Receives disability benefit & $1.52^{\mathrm{c}}$ & ** & 1.23 & $* *$ & 1.33 & ** & 1.14 & \\
\hline Self-employed & 1.10 & & 1.19 & $* *$ & 1.17 & ** & 0.93 & \\
\hline Retired & 1.21 & & 0.97 & & 1.07 & & 1.13 & \\
\hline Receives other benefit & 1.24 & & 0.88 & $* *$ & 0.16 & & 1.18 & \\
\hline Parental income & 0.88 & & 0.63 & $\star *$ & 1.13 & ** & 0.78 & ** \\
\hline Child is female & $1.30^{c}$ & ** & 0.85 & $* *$ & 1.06 & $* *$ & 1.23 & ** \\
\hline Parents have other child living close & $0.44^{\mathrm{c}}$ & ** & 1.03 & & 0.74 & ** & 0.60 & ** \\
\hline Child is only child & 1.26 & ** & 0.97 & & 0.82 & ** & 1.54 & ** \\
\hline \multicolumn{9}{|l|}{ Control variables } \\
\hline Age & 0.83 & ** & 0.81 & $* *$ & 0.78 & ** & 1.06 & \\
\hline Age squared & 1.01 & ** & 1.01 & $* *$ & 1.01 & ** & 1.00 & \\
\hline Age difference & $1.00^{\mathrm{C}}$ & & 1.00 & & 0.99 & ** & 1.01 & * \\
\hline Has recently moved & 0.03 & ** & 0.02 & $* *$ & 0.03 & ** & 1.06 & \\
\hline Homeowner & 0.93 & & 0.82 & $* *$ & 0.90 & ** & 1.03 & \\
\hline Rural resident & 0.91 & & 0.81 & $* *$ & 1.12 & $* *$ & 0.81 & ** \\
\hline \multicolumn{9}{|l|}{ Child's migrant status $^{a}$} \\
\hline non-Western migrant & 1.30 & * & 1.06 & & 0.93 & & 1.40 & * \\
\hline Western migrant & 1.00 & & 0.82 & $* *$ & 0.97 & & 1.03 & \\
\hline $\mathrm{N}$ & \multicolumn{8}{|c|}{$2,725,400$} \\
\hline$d f$ & \multicolumn{8}{|c|}{108} \\
\hline$x^{2}$ & \multicolumn{8}{|c|}{140,729} \\
\hline
\end{tabular}

Note: The standard errors are corrected for the clustering of children with the same mother.

${ }^{a}$ Reference categories: with partner; no child, employed; parents together; parents employed; native Dutch. ${ }^{\mathrm{b}}$ Parameters for moving close, with moving elsewhere as the reference category. 'Coefficient differs significantly from coefficient in child's regression $(p<.001$ Wald test).

${ }^{*} p<.01{ }^{* *} p<.001$ 


\section{Results}

The multivariate results in Table 6 show that never-married and widowed singles are more likely than those with a partner to move very close to parents, but these moves are not significantly more likely than moves elsewhere (see first row of Table 6). At the same time, parents are less likely to move very close to a never-married adult child than to an adult child who lives with a partner (see first row, first column of Table 7). This result might be explained by the role of support needs: never-married children are likely to be less (financially) independent of their parents than are their partnered counterparts. The former probably move very close to their parents in order to receive support from them, but are less likely to provide them with it. As expected, divorced adult children are more likely to move very close to parents than are partnered children and the effect of moving very close is significantly greater than that of moving elsewhere, particularly when the divorce took place recently. (Note that to enhance the readability of this paper, the term 'effect' is used to indicate statistical effect estimates, not to indicate claims about causality.)

The presence of children in the adult child's household was expected to make moving less likely, except in the year following first childbirth. Indeed, a recent first birth in the adult child's household increases the likelihood of moving in general, but moves very close to parents are not significantly more likely than moves elsewhere. Having children aged one year or older living in the household decreases the likelihood of moving very close to parents or elsewhere, particularly when the children are of school age (age four or older). Note that for those with children aged 1 to 4 , moves very close to parents are less likely than for those without children when compared with making no move at all, but more likely when compared with moves elsewhere (see last column of Table 6).The likelihood that parents move very close to their adult child was expected to be greater for those whose adult child has children below school age (age one to four). This expectation is confirmed, but also parents whose adult child has children of school age (age four and above) are more likely to move close (see Table 7).

In contrast with what was expected, the child's labor-market position and income are barely associated with the odds of moving very close to parents, although income is positively associated with moving elsewhere. Also, being economically inactive increases the odds of moving elsewhere compared with not moving. It is possible that these moves mainly refer to non-employed housewives who move along with their partners. Children who receive a disability benefit are more likely to move very close to parents than are their employed counterparts, but the association is only marginally significant. In the additional analyses for mothers and fathers separately, the positive association with the child's disability benefit appeared to be greater for moves close to mothers than for moves close to fathers. 
Adult children are less likely to move very close to a father with a new partner or a father who is divorced or never married than to parents who still live together. Significant positive effects on moves very close to an adult child were found for mothers with a new partner (which was surprising) and widowed mothers and divorced or never-married mothers and fathers (which was expected). Apparently, divorce and, to a lesser extent, widowhood, increase the need for contact and support and the wish to live close to an adult child. It should be noted, however, that the effects on moves very close are not greater than those on moves close or elsewhere. The associations of the mother's and the father's recent divorce with moves very close are positive, but not significant. This lack of significance can be explained by small group sizes resulting from randomly choosing one of both parents. In the additional models for mothers and fathers separately, the effects of a parent's recent divorce on moving very close to an adult child were significant, but again, not stronger than those on moves close or moves elsewhere.

Parents who receive a disability benefit are more likely to move very close to an adult child than are parents who are employed, possibly because they are likely to need care and desire to live close to their children. The parents' income is not associated with moves close to parents or adult children, but it is positively associated with the odds that either generation moves elsewhere. This finding confirms the idea that people with a higher income have a less strong need for the proximity of kin. In addition, people with higher incomes have more opportunities to move than those who are less well off. The greater likelihood of moves elsewhere might be explained by the fact that highincome children move further away for job-related reasons, whereas high-income parents move further away for reasons related to the quality of their housing or residential area.

The gender of the adult child does not seem to influence the extent to which adult children move close to their parents, but parents are significantly more likely to move close to a daughter than to a son, which was expected.

As expected, moves of the adult child in the direction of the parents are more likely when at least one other child already lives close to the parents, whereas the presence of at least one other child within one kilometer of the parents reduces the parents' likelihood of moving away. Only children are not significantly more likely to move very close to their parents, but parents of an only child are more likely than other parents to move very close to their child and less likely to move elsewhere.

The analyses furthermore show that people are less likely to move when they are older, have recently moved, and are homeowners. Compared with making no move at all, living in a rural area is not significantly associated with moves very close to parents and children. Compared with moving elsewhere, however, children in rural areas are more likely to move very close to parents than those in urban areas, whereas the 
opposite is true for parents in rural areas. So, children in rural areas are less likely to move, but if they move the chances are greater that they move very close to their parents. This finding provides partial support for the expectation that living in rural areas is associated with stronger filial responsibility and with a greater likelihood of moves close to kin.

To address the question of which generation is most likely to move very close to the other and under what circumstances this move occurs, Table 8 gives an overview of the situations and events with significant positive effects on moving very close to the other generation, and for which these positive effects are significantly stronger than those on moving elsewhere. To distinguish who is most likely to move very close under a given situation, the adult child or the parents, the table only includes the characteristics for which the parameters differ significantly between the child's and the parents' model. The effect of divorce is most pronounced in the analyses. Divorced adult children are more likely to move very close to parents than are children who live with a partner, and the effect on moving very close is significantly stronger than that on moving elsewhere. Obviously, the event of divorce is often followed by a move, but moves very close to parents are extra likely after the adult child's divorce. Note that this tendency is not true for parents who have recently experienced a divorce; they are more likely to move elsewhere than to move very close to their adult child (see Table 7).

Table 8: Who is most likely to move to within one kilometer?

\begin{tabular}{lc}
\hline Characteristic & Who moves to within one kilometer? \\
\hline Child's household situation (ref. with partner) & Child \\
Divorced single & Child \\
Divorced '04-'05 & \\
Child has children in the household (ref. none) & Parents \\
Children aged 1 to 4 & Parents \\
Children above age 4 & Parents \\
Child is female & Child \\
Parents have other child living close & \\
\hline
\end{tabular}

The presence of children in the adult child's household is also positively associated with moving very close. Interestingly, when the adult child has children aged one year and more, it is the parents who move very close to the adult child and not the other way around. Furthermore, parents are more likely to move very close to daughters than to sons, and these moves are significantly more likely than moves elsewhere. The analyses also reveal that an adult child who already has a sibling living close to the parents is more likely to move close than when no other siblings already live close. It is possible 
that these children move back to where they spent their youths and where their siblings still live (or moved back to).

\section{Discussion}

This paper examines the extent to which support needs lead to adult children and parents moving close to each other, and addresses the question of who is most likely to do so. The results clearly suggest that the support needs of either generation are associated with moves closer to parents or adult children. For adult children, being divorced or having recently divorced is associated with moves close to the parents. Parents are more likely to move close to an adult child when the adult has children aged one year or older, when the adult child is female, and when the adult child is an only child. Also, parents with a disability benefit are more likely than employed parents to move close to an adult child.

The results suggest that when people move close to kin, the person in need is the most likely to move. Thus, the support needs of an adult child are associated with the child's move close to the parent, but not with moves of the parents close to them. The moves of parents close to their adult children with children form an exception. It is possible that these parents move close to their children to help out with childcare, which is consistent with findings from several European countries (Hank and Buber 2009), but the literature also suggests that older parents wish to spend time with their grandchildren (Lin and Rogerson 1995), which makes the issue of whose needs are better met by such moves less clear.

There is also an indication that parents move closer to an adult child because they have better opportunities to do so. Where adult children often have strong ties to their local environment for reasons of work, childcare, and schools for the children, their parents do not. Future research should further explore the role of needs and opportunities in moving close to parents and children.

The findings presented in this study suggest moves close to parents and children in the Netherlands can be a response to increased support needs. This conclusion is in line with findings for Sweden (Pettersson and Malmberg 2009). Future studies could address the issue to what extent the association between support needs and moves close to kin also exists in other countries.

Although the importance of support needs for moving close to parents and children has been clarified by the present analysis, it also has its weaknesses. Support needs that require the proximity of kin often arise from health problems or the inability to perform activities of daily living. Unfortunately, the data did not include such information. Also, it might take some time before parents or adult children react to their own or the other 
generation's support needs and initiate a move towards them. When a longer period of observation would have been used, more moves in reaction to changes in support needs might have been captured. At the same time, however, the measurement of the event variables would have been less precise: it would be less clear whether the observed moves would actually be related to the event. The data did not include the adult children's or parents' level of education, although previous research indicated that this is strongly related to migration behavior (e.g., Sjaastad 1962). The actual motives for moving close to parents and children were also not known. The opportunity of taking into account the motives for moving close to kin would contribute radically to the knowledge on intergenerational proximity and mobility. Despite these limitations, the analyses presented in this paper do reveal that support needs have a substantial impact on moving close to parents and children.

\section{Acknowledgements}

The research for this paper was made possible by NWO VICI grant no. 453-04-001. This paper is part of a joint project with Statistics Netherlands; I am very grateful to the department of Socio-Economic State for enabling me to work with the Social Statistical dataBase. I want to thank Clara Mulder and various colleagues in Amsterdam and Utrecht (participants of the so-called leerzitje) for providing useful feedback on earlier versions of the paper. 


\section{References}

Aboderin, I. (2004). Modernisation and ageing theory revisited: Current explanations of recent developing world and historical Western shifts in material family support for older people. Ageing \& Society 24(1): 29-50. doi:10.1017/S0144686X03001521.

Amato, P.R. (2000). The consequences of divorce for adults and children. Journal of Marriage and Family 62(4): 1269-1287. doi:10.1111/j.1741-3737.2000.01269.x.

Bakker, B.F. (2002). Statistics Netherlands' approach to Social Statistics: The Social Statistical Dataset. OECD Statistics Newsletter 11: 4-6.

Bordone, V. (2009). Contact and proximity of older people to their adult children: A comparison between Italy and Sweden. Population, Space and Place 15(4): 359380. doi:10.1002/psp.559.

Boyle, P., Halfacree, K., and Robinson, V. (1998). Exploring Contemporary Migration. Harlow: Longman.

Burgess, E.W. (1960). Aging in western culture. In: Burgess, E.W. (ed.). Ageing in Western Societies. Chicago: University Press: 3-28.

Clark, R. and Wolf, D. (1992). Proximity of children and elderly migration. In: Rogers, A. (ed.). Elderly migration and population redistribution: A comparative study. London: Belhaven: 77-96.

Clark, W.A.V. and Dieleman, F.M. (1996). Households and housing. New Brunswick, NJ: CUPR Press.

Clogg, C.C., Petkova, E., and Haritou, A. (1995). Statistical methods for comparing regression coefficients between models. American Journal of Sociology 100(5): 1261-1293. doi:10.1086/230638.

Courgeau, D. (1985). Interaction between spatial mobility, family and career life-cycle: A French survey. European Sociological Review 1(2): 139-162.

Cowgill, D.O. (1974). The aging of populations and societies. The Annals of the American Academy of Political and Social Science 415(1): 1-18. doi:10.1177/000271627441500102.

Da Vanzo, J. (1981). Repeat migration, information costs, and location-specific capital. Population and Environment 4(1): 45-73. doi:10.1007/BF01362575. 
Deurloo, M.C., Clark, W.A.V., and Dieleman, F.M. (1994). The move to housing ownership in temporal and regional contexts. Environment and Planning A 26(11): 1659-1670. doi:10.1068/a261659.

Feijten, P. and Mulder, C.H. (2002). The timing of household events and housing events in the Nertherlands: A longitudinal perspective. Housing studies 17(5): 773-792. doi:10.1080/0267303022000009808.

Gram-Hanssen, K. and Bech-Danielsen, C. (2008). Home dissolution: What happens after separating? Housing Studies 23(3): 507-522. doi:10.1080/02673030802020635.

Grundy, E. and Shelton, N. (2001). Contact between adult children and their parents in Great-Britain 1986-1999. Environment and Planning A 33(4): 685-697. doi:10.1068/a33165.

Hank, K. (2007). Proximity and contacts between older parents and their children: A European comparison. Journal of Marriage and Family 69(1): 157-173. doi:10.1111/j.1741-3737.2006.00351.x.

Hank, K. and Buber, I. (2009). Grandparents caring for their grandchildren: Findings from the 2004 survey of health, ageing, and retirement in Europe. Journal of Family Issues 30(1): 53-73. doi:10.1177/0192513X08322627.

Helderman, A.C., Van Ham, M., and Mulder, C.H. (2006). Migration and home ownership. Tijdschrift voor Economische en Sociale Geografie 97(2): 111-125. doi:10.1111/j.1467-9663.2006.00506.x.

Joseph, A.E. and Chalmers, A.I. (1996). Restructuring long-term care and the geography of ageing: A view from rural New Zealand. Social Science and Medicine 887-896. doi:10.1016/0277-9536(95)00187-5. 42(6):

Joseph, A.E. and Hallman, B.C. (1998). Over the hill and far away: Distance as a barrier to the provision of assistance to elderly relatives. Social Science and Medicine 46(6): 631-639. doi:10.1016/S0277-9536(97)00181-0.

Knijn, T.C.M. and Liefbroer, A.C. (2006). More than kind: Instrumental support in families. In: Dykstra, P.A., Kalmijn, M., Knijn, T., Komter, A., Liefbroer, A., and Mulder, C.H. (eds.). Family Solidarity in the Netherlands. Amsterdam: Dutch University Press: 89-106. 
Lee, G.R., Coward, R.T., and Netzer, J.K. (1994). Residential differences in filial responsibility expectations among older persons. Rural Sociology 59(1): 100109. doi:10.1111/j.1549-0831.1994.tb00524.x.

Liefbroer, A.C. and Mulder, C.H. (2006). Family obligations. In: Dykstra, P.A., Kalmijn, M., Knijn, T., Komter, A., Liefbroer, A., and Mulder, C.H. (eds.). Family Solidarity in the Netherlands. Amsterdam: Dutch University Press: 123146.

Lin, G. and Rogerson, P. (1995). Elderly parents and the geographic availability of their adult children. Research on Aging 17(3): 303-331. doi:10.1177/0164027595173004.

Litwak, E. (1985). Helping the Elderly: Complementary Roles of Informal Networks and Formal Systems. New York: Guildford.

Litwak, E. and Longino, C.F. Jr. (1987). Migration Patterns Among the Elderly: A Developmental Perspective. The Gerontologist 27: 266-72. http://dx.doi.org/10.1093/geront/27.3.266

Long, L.H. (1972). The influence of number and ages of children on residential mobility. Demography 9(3): 371-382. doi:10.2307/2060860.

Longino, C.F.Jr., Jackson, D.J., Zimmerman, R.S., and Bradsher, J.E. (1991). The second move: Health and geographic mobility. Journal of Gerontology: Social Sciences 46(4): 218-244. doi:10.1093/geronj/46.4.S218.

Malmberg, G. and Pettersson, A. (2007). Distance to elderly parents: Analyses of Swedish register data. Demographic Research 17(23): 679-704. doi:10.4054/DemRes.2007.17.23.

Michielin, F. and Mulder, C.H. (2007). Geographical distances between adult children and their parents in the Netherlands. Demographic Research 17(22): 655-678. doi:10.4054/DemRes.2007.17.22.

Michielin, F., Mulder, C.H., and Zorlu, A. (2008). Distance to parents and geographical mobility. Population, Space and Place 14(4): 327-345. doi:10.1002/psp.509.

Mulder, C.H. (1993). Migration Dynamics: A Life course Approach. Amsterdam: Thesis Publishers.

Mulder, C.H. and Kalmijn, M. (2006). Geographical distances between family members. In: Dykstra, P.A., Kalmijn, M., Knijn, T., Komter, A., Liefbroer, A., and Mulder, C.H. (eds.). Family Solidarity in the Netherlands. Amsterdam: Dutch University Press: 43-62. 
Smits: Moving close to parents and adult children in the Netherlands: The influence of support needs

Mulder, C.H. and Van der Meer, M.J. (2009). Geographical distances and support from family members. Population, Space and Place 15(4): 381-399. doi:10.1002/psp.557.

Mulder, C.H. and Wagner, M. (1993). Migration and marriage in the life course: A method for studying synchronized events. European Journal of Population 9(1): 55-76. doi:10.1007/BF01267901.

Mulder, C.H. and Wagner, M. (1998). First-time home-ownership in the family life course: A West German-Dutch comparison. Urban Studies 35(4): 687-713. doi:10.1080/0042098984709.

Pettersson, A. and Malmberg, G. (2009). Adult children and elderly parents as mobility attractions in Sweden. Population, Space and Place 15(4): 343-357. doi:10.1002/psp.558.

Rogerson, P.A., Burr, J.A., and Lin, G. (1997). Changes in geographic proximity between parents and their adult children. International Journal of Population Geography 3(2): 121-136. doi:10.1002/(SICI)1099-1220(199706)3:2<121::AIDIJPG60>3.0.

$\mathrm{CO} ; 2-\mathrm{I}$.

Rossi, A. and Rossi, P. (1990). Of human bonding: Parent-child relations across the life course. New York: Aldine de Gruyter.

Serow, W.J. and Sly, D.F. (1991). Geographic mobility of the elderly in industrialized societies. In: Lutz, W. (ed.). Future Demographic Trends in Europe and North America: What Can We Assume Today? London: Academic Press: 399-419.

Shelton, N. and Grundy, E. (2000). Proximity of adult children to their parents in Great Britain. International Journal of Population Geography 6(3): 181-195. doi:10.1002/1099-1220(200005/06)6:3<181::AID-IJPG181>3.0.CO;2-U.

Silverstein, M. (1995). Stability and change in temporal distance between the elderly and their children. Demography 32(1): 29-45. doi:10.2307/2061895.

Sjaastad, L.A. (1962). The costs and returns of human migration. Journal of Political Economy 70(S5): 80-93. doi:10.1086/258726.

Smits, A., van Gaalen, R.I., and Mulder, C.H. (forthcoming). Parent - child coresidence: Who moves in with whom and for whose needs? Journal of Marriage and Family.

Speare, A.Jr., Goldstein, S., and Frey, W.H. (1975). Residential Mobility, Migration and Metropolitan Change. Cambridge, MA: Ballinger. 
Van Diepen, A.M.L. and Mulder, C.H. (2009). Distance to family members and relocations of older adults. Journal of Housing and the Built Environment 24(1): 31-46. doi:10.1007/s10901-008-9130-0.

Weesie, J. (1999). Seemingly unrelated estimation and the cluster-adjusted sandwich estimator. Stata Technical Bulletin 52: 34-47. 
Smits: Moving close to parents and adult children in the Netherlands: The influence of support needs 